University of Nebraska - Lincoln

DigitalCommons@University of Nebraska - Lincoln

USDA National Wildlife Research Center - Staff Publications
U.S. Department of Agriculture: Animal and Plant Health Inspection Service

January 2005

\title{
Probabilistic model for estimating field mortality of target and non-target bird populations when simultaneously exposed to avicide bait
}

\author{
John J. Johnston \\ USDA/APHIS/WS National Wildlife Research Center \\ Melvin J. Holmes \\ DEFRA, Central Science Laboratory \\ Andy Hart \\ DEFRA, Central Science Laboratory \\ Dennis J. Kohler
}

USDA/APHIS/WS National Wildlife Research Center, dennis.kohler@aphis.usda.gov

Randal S. Stahl

USDA-APHIS-Wildlife Services, randal.s.stahl@aphis.usda.gov

Follow this and additional works at: https://digitalcommons.unl.edu/icwdm_usdanwrc

Part of the Environmental Sciences Commons

Johnston, John J.; Holmes, Melvin J.; Hart, Andy ; Kohler, Dennis J.; and Stahl, Randal S., "Probabilistic model for estimating field mortality of target and non-target bird populations when simultaneously exposed to avicide bait" (2005). USDA National Wildlife Research Center - Staff Publications. 17.

https://digitalcommons.unl.edu/icwdm_usdanwrc/17

This Article is brought to you for free and open access by the U.S. Department of Agriculture: Animal and Plant Health Inspection Service at DigitalCommons@University of Nebraska - Lincoln. It has been accepted for inclusion in USDA National Wildlife Research Center - Staff Publications by an authorized administrator of DigitalCommons@University of Nebraska - Lincoln. 


\title{
Probabilistic model for estimating field mort- ality of target and non-target bird populations when simultaneously exposed to avicide bait
}

\author{
John J Johnston, ${ }^{1 *}$ Melvin J Holmes, ${ }^{2}$ Andy Hart, ${ }^{2}$ Dennis J Kohler ${ }^{1}$ and \\ Randal S Stahl ${ }^{1}$ \\ ${ }^{1}$ USDA/APHIS/Wildlife Services, National Wildlife Research Center, 4101 LaPorte Avenue, Fort Collins, CO 80521, USA \\ ${ }^{2}$ DEFRA, Central Science Laboratory, Sand Hutton, York, YO41 1LZ, UK
}

\begin{abstract}
A probabilistic model was developed to estimate target and non-target avian mortality associated with the application of the avicide CPTH (3-chloro- $p$-toluidine hydrochloride) to minimize sprouting rice damage in the southern USA. CPTH exposures for individual birds were predicted by random sampling from species-specific non-parametric distributions of bait seed consumption and CPTH residues detected on individual bait seeds. Mortality was predicted from the species-specific exposure versus mortality relationship. Individual variations in this response were captured in the model by Monte Carlo sampling from species-specific distributions of slopes and median toxicity values $\left(\mathrm{LD}_{50}\right)$ for each bird. The model was used to simultaneously predict mortality (percentage of exposed population and number of birds killed/weight of consumed bait) for a target (blackbird) and non-target (mourning dove) species feeding on bait sites for up to five consecutive days.

(c) 2005 Society of Chemical Industry
\end{abstract}

Keywords: probabilistic risk assessment; model; CPTH; DRC-1339; 3-chloro-4-methylaniline; blackbird; toxicity

\section{INTRODUCTION}

The pesticide 3-chloro- $p$-toluidine hydrochloride, (CPTH, 3-chloro-4-methylaniline hydrochloride; DRC-1339; Fig 1) was developed by the United States Fish and Wildlife Service for controlling European starlings (Sturnus vulgaris L) in livestock feedlots. ${ }^{1}$ The United States Department of Agriculture/Animal and Plant Health Inspection Service/Wildlife Services (USDA/APHIS/WS) has used CPTH-coated rice baits to reduce red-winged blackbird (Agelaius phoeniceus $\mathrm{L}$ ) damage to rice in Louisiana and to sunflower in North and South Dakota. ${ }^{2,3}$ Additional target species include grackles (Quiscalus spp), yellow-headed blackbirds (Xanthocephalus xanthocephalus Bonap) and brownheaded cowbirds (Molothrus ater Bodd). ${ }^{4,5}$ Typically, CPTH is coated onto brown rice at a target concentration of $20 \mathrm{~g} \mathrm{~kg}^{-1}$. At the application site, the CPTHtreated brown rice is diluted with untreated rice at a ratio of $1: 25(\mathrm{w} / \mathrm{w})$. This CPTH rice bait mixture is subsequently broadcast at a rate of $12-23 \mathrm{~kg} \mathrm{ha}^{-1}$. Up to four repeat applications can be distributed following consumption of $75 \%$ of the previous application or $10 \mathrm{~mm}$ of precipitation (United States Environmental Protection Agency Registration No 56228-30).

Concern regarding the use of $\mathrm{CPTH}$ has focused on hazards to non-target species which have been observed in or near CPTH-baited fields. ${ }^{5-8}$ These non-target species include Savannah sparrow (Passerculus sandwichensis Gmelin), killdeer (Charadrius vociferous L), mourning dove (Zenaida macroura L), meadowlark (Stumella spp), American pipit (Anthus rubescens Tunstall), northern cardinal (Cardinalis cardinalis $\mathrm{L}$ ), horned lark (Eremophila alpestris L), herring gull (Larus argentatus Pont), ring-necked pheasant (Phasianus colchicus L), American robin (Turdus migratorius L), house sparrow (Passer domesticus L), American tree sparrow (Spizella arborea Wilson), Canada goose (Branta canadensis L), mallard (Anas platyrhynchos L), northern flicker (Colaptes auratus L), meadowlark (Sturnella spp), downy woodpecker (Picoides pubescens $\mathrm{L}$ ), dark eyed junco (funco hyemalis $\mathrm{L}$ ), green winged teal (Anas crecca L), song sparrow (Melospiza melodia Wilson), vesper sparrow (Pooecetes gramineus (Gmelin)), grasshopper sparrow (Ammodramus savannarum (Gmelin)), field sparrow (Spizella pussila Wilson) and rock dove (Columba livia Gmelin). ${ }^{5-7}$ While the presence of such bird species suggests a potential hazard, a more detailed analysis is required to quantify the risk of acute toxicity.

In order to maximize target and minimize nontarget CPTH-induced mortality, sites are pre-baited to attract target species, and bait application is timed to minimize exposure of non-target birds. More than a decade of monitoring bait sites during and after

* Correspondence to: John J Johnston, USDA/APHIS/Wildlife Services, National Wildlife Research Center, 4101 LaPorte Avenue, Fort Collins, CO 80521, USA

E-mail: john.j.johnston@aphis.usda.gov

(Received 14 July 2004; revised version received 5 January 2005; accepted 5 January 2005)

Published online 4 March 2005 
<smiles>Cc1ccc([NH3+])cc1Cl</smiles>

Figure 1. Structure of $\mathrm{CPTH}$.

CPTH baiting operations has produced evidence of very few non-target casualties. However, this practice has also led to the discovery of very few target species as well. This is likely due to the mobility of target and non-target avian species and the slow-acting nature of CPTH, death typically occurring one to several days post-ingestion. ${ }^{9}$ This situation makes it very difficult to assess the numbers of both target and non-target species that are killed as a result of a CPTH baiting operation. As WS has no intention of applying a pesticide with low efficacy to target species and/or significant adverse effects to non-target species, a probabilistic model was developed using toxicity data from confined feeding studies and bait seed consumption data from both confined feeding studies and field observations as a means of estimating both target and non-target mortality associated with $\mathrm{CPTH}$ baiting programs to minimize avian-induced rice, corn and sunflower damage in the USA.

\section{METHODS}

\subsection{Probabilistic model}

The probabilistic model to determine the probability of death for individual birds feeding on CPTH-baited rice seed was developed using Crystal Ball Professional Software (Decisioneering Inc, Denver, CO), an integrated MS Excel (Microsoft, Redmond, WA) addin program which permits Monte Carlo analysis for simulations of real-world scenarios involving various elements of uncertainty.

\subsubsection{CPTH exposure-multiple species}

To model CPTH exposure for multiple species simultaneously feeding on a bait site, a species distribution was prepared using the custom distribution function in Crystal Ball. The distribution contained the proportions of each species observed in the CPTH-baited field. For each bird (a single iteration of the model), a species was selected based on the relative probabilities in this distribution. The bird was then randomly assigned a bodyweight from a normally distributed species-specific bodyweight distribution (Fig 2). ${ }^{10}$

\subsubsection{CPTH exposure - single day of baiting}

Individual bird consumption patterns were estimated from available rice seed consumption data for redwinged blackbirds and mourning doves. Normal distributions of rice seeds consumed per bird were constructed using the mean and standard errors for feeding time (minutes) and feeding rate (seeds per minute) for red-winged blackbirds feeding under aviary conditions. ${ }^{11}$ To generate a distribution for consumption of 1:25 diluted CPTH-treated rice seeds, the estimated number of untreated seeds was multiplied by 0.45 , the mean consumption ratio of CPTH-treated versus untreated seeds for six bird species. ${ }^{12}$ The mean and standard deviation of the resulting estimation for red-winged blackbird consumption of CPTH-treated rice seeds under aviary conditions was 39.8 and 5.3 seeds per bird, respectively. In another study, Custer et $a l^{6}$ captured a limited number of target and nontarget species on CPTH rice seed baited plots and determined the number of seeds consumed per bird following necropsy. For the red-winged blackbirds which consumed rice seeds, the mean ( \pm standard error) consumption was 17.1 ( \pm 10.7$)$ seeds per bird. The distribution of seed consumption data (seeds consumed per bird versus frequency) for the field-collected red-winged blackbirds was better approximated by a log-normal than a normal distribution.

Due to the safe and tranquil environment associated with the aviary feeding study, the aviary-fed birds likely consumed more rice seed than they would have consumed in an actual field baiting situation. As the field-collected birds were shot in the process of feeding, these birds likely consumed less rice seed than they would have consumed in a normal field baiting situation. For this model, a log-normal distribution of CPTH treated rice seeds consumed (23.5 = mean, $8.4=$ standard error) was constructed by averaging the consumption values from the aviary and field studies.

To estimate $\mathrm{CPTH}$ rice seed consumption by mourning doves, only field-collected data from Custer et al were available. For mourning doves shot on fields baited with CPTH-treated rice, the mean number of rice seeds consumed per bird was estimated to be 71.7 . As the ratio of mean seed consumption used for the blackbird model/mean seed consumption observed in the field-collected blackbirds was 3, the seed values from field-collected mourning doves were multiplied by a factor of 3 to generate a mean for the log-normal distribution of CPTH-treated rice seed consumption for the model.

For each bird, the total number of bait seeds consumed was determined by random selection of a value from the species-specific estimated rice seed consumption distribution. The number of treated seeds consumed by each bird was estimated by random selection of a value from a binomial distribution based on the number of seeds consumed and the fraction of treated:diluent seeds in the mix ( 1 part treated seed:25 parts diluent rice seeds). The model also contained a function to reduce the number of treated seeds consumed based on avoidance of CPTH-treated rice seeds; the number of treated seeds avoided was determined by subtracting a randomly selected value from a binomial distribution based on trials (number 


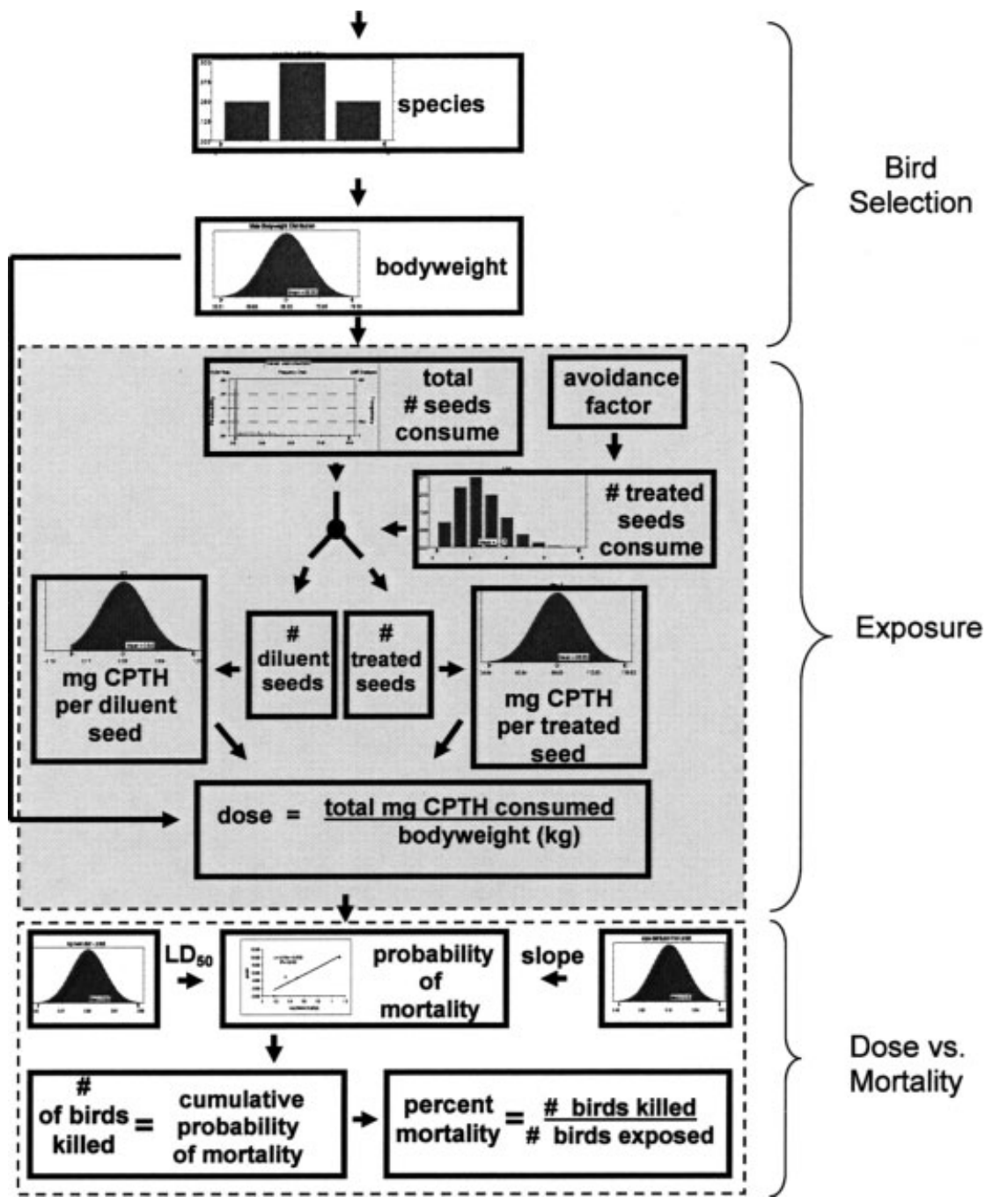

Figure 2. Single day probabilistic model for mortality determination of birds feeding on CPTH bait sites.

of treated seeds) and probability (avoidance factor). ${ }^{13}$ The number of diluent seeds consumed by each bird was determined by subtracting the number of treated seeds from the total number of seeds consumed. The distribution of CPTH on treated and diluent seeds was constructed from the analysis of individual seeds after mixing for $3 \mathrm{~min}$ in a cement mixer, a common practice for preparation of CPTH baits. The CPTH content on treated and diluent seeds was determined by randomly selected CPTH content values from the treated and diluent CPTH seed distributions. Daily exposure was calculated as the sum of the CPTH content of all seeds consumed by each bird.

To assess the validity of the estimated rice seed consumption distributions, CPTH-associated mortality was also calculated using distributions of bait seed consumption developed from necropsy data for target and non-target species collected after feeding on CPTH-baited fields in Louisiana during 2000 and 2003. (Pipas PA, pers comm, 2004)

\subsubsection{CPTH exposure-multiple days of baiting}

As the CPTH label restrictions permit baiting for a maximum of 5 consecutive days, birds could be exposed to freshly applied CPTH baits for a maximum of 5 consecutive days (Fig 3). In modeling these multiple day exposures, the cumulative toxic effect (ie cellular damage) was estimated as the sum of absorbed doses from previous days plus the dose for that day. The fraction of dose absorbed for previous exposures was calculated from European starling (Sturnus vulgaris L) CPTH chronic toxicity studies. ${ }^{14}$ Even though nearly all of the ingested CPTH is excreted within $6 \mathrm{~h}$ post-exposure, ${ }^{15}$ the cumulative effect of toxicity suggests that the cellular damage is irreversible or very slowly repaired. Interspecies extrapolation of these data was accomplished by calculating all exposures as a fraction of the $\mathrm{LD}_{50}$ for each species. When the cumulative equivalent single dose was greater than or equal to the $\mathrm{LD}_{99.9}$ for that individual, consumption of feeding was terminated for that bird.

\subsubsection{Estimation of mortality}

The probability of mortality for an individual bird was calculated as a function of exposure and sensitivity (dose versus mortality). The average sensitivity of each species to CPTH was determined by constructing a dose versus mortality curve (log dose versus probit mortality) for each species of interest. ${ }^{16,17}$ To model 


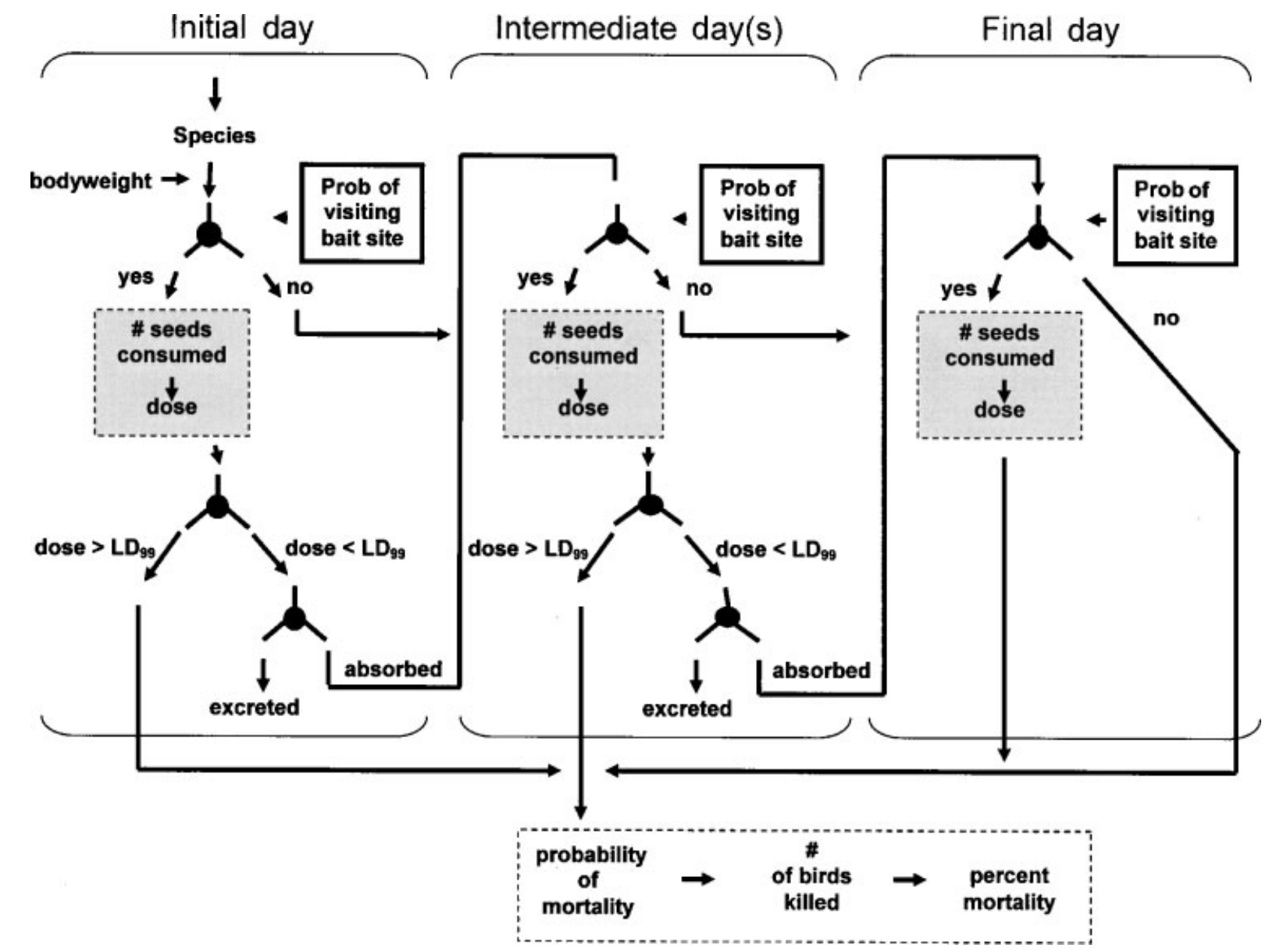

Figure 3. Multiple day probabilistic model.

the sensitivity of an individual bird to CPTH, a separate curve was constructed for each iteration by randomly selecting a slope and median value $\left(\mathrm{LD}_{50}\right)$ from normal distributions of these parameters. The normal distribution of $\log$ median dose values was constructed using the population $\log \mathrm{LD}_{50}$ as the maximum and the reciprocal of the slope of the species log dose versus probit mortality curve as the standard deviation. The normal distribution of slope values used the slope of the species probit toxicity curve as a maximum and variance of the slope as calculated according to Finney. ${ }^{16}$ For each bird, a new dose versus mortality curve was constructed using an $\mathrm{LD}_{50}$ and slope that were randomly selected from the appropriate normal distributions. This relationship was used to determine the probability of mortality for the individual bird based on the estimated $\mathrm{CPTH}$ exposure (log dose). For a population of CPTHexposed birds, the total number of birds killed was calculated as the sum of the individual probabilities of mortality. The percentage mortality for the exposed population was calculated as the mean of the individual probabilities of mortality.

The Crystal Ball 2D (two-dimensional Monte Carlo) simulation function was used to determine the uncertainty associated with the mortality estimates. The mean and the slope of the probit mortality curve were used as uncertainty parameters while all other input distributions (assumptions) were classified as variability. For each mortality estimate, the $2 \mathrm{D}$ simulation was run for 400 uncertainty iterations. Each uncertainty iteration consisted of 500 variability iterations. The values for percentage mortality and total number of birds killed for each of the 400 uncertainty iterations were used to estimate the distribution of mean probabilities for the species and baiting scenarios of interest.

\subsubsection{Estimation of absorption}

Regression parameters derived for Table 1 were calculated on the basis of data presented by Schaefer et al. ${ }^{14}$ In that study, seven groups of ten starlings each were fed diets fortified with CPTH at levels ranging from 1 to $40 \mathrm{mg} \mathrm{kg}^{-1}$ until all birds died. Mean time to death for each treatment group ranged from 7.2 to 77 days. Feed consumption was monitored for the entire study and permitted calculation of the mean total dose per bird for each treatment group (Table 1). Since 10 out of 10 birds died in each group, we assumed that the mean absorbed dose for the duration of the study was at least equal to the acute $\mathrm{LD}_{99}\left(3.2 \mathrm{mg} \mathrm{kg}^{-1}\right)$. The fraction of dose absorbed in each treatment group was estimated as the $\mathrm{LD}_{99}$ divided by the mean total dose per bird. Mean time to death and mean fraction of dose absorbed permitted 
Table 1. Observed and regression calculated fraction of ingested dose absorbed

\begin{tabular}{|c|c|c|c|c|c|c|}
\hline \multirow[b]{2}{*}{ Species } & \multirow{2}{*}{$\begin{array}{c}\text { Mean dose } \\
\left(\mathrm{mg} \mathrm{kg}^{-1}\right)\end{array}$} & \multirow{2}{*}{$\begin{array}{c}\mathrm{LD}_{50}{ }^{\mathrm{b}} \\
\left(\mathrm{mg} \mathrm{kg}^{-1}\right)\end{array}$} & \multirow{2}{*}{$\begin{array}{c}\text { Fraction of } \\
\text { LD }_{50} \text { ingested }\end{array}$} & \multicolumn{2}{|c|}{$\begin{array}{l}\text { Observed fraction } \\
\text { of dose absorbed }\end{array}$} & \multirow{2}{*}{$\begin{array}{l}\text { Regression calcula- } \\
\text { ted fraction of } \\
\text { dose absorbed }\end{array}$} \\
\hline & & & & Mean & $95 \% \mathrm{Cl}$ & \\
\hline Red-winged blackbird & 4.0 & 3.4 & 1.18 & 0.94 & $0.91-0.97$ & 0.91 \\
\hline Dark-eyed junco & 17.0 & 162 & 0.1 & 0.99 & $0.97-1.0$ & 0.99 \\
\hline
\end{tabular}

a From Reference 15.

b From Reference 17.

c Derived from Reference 14.

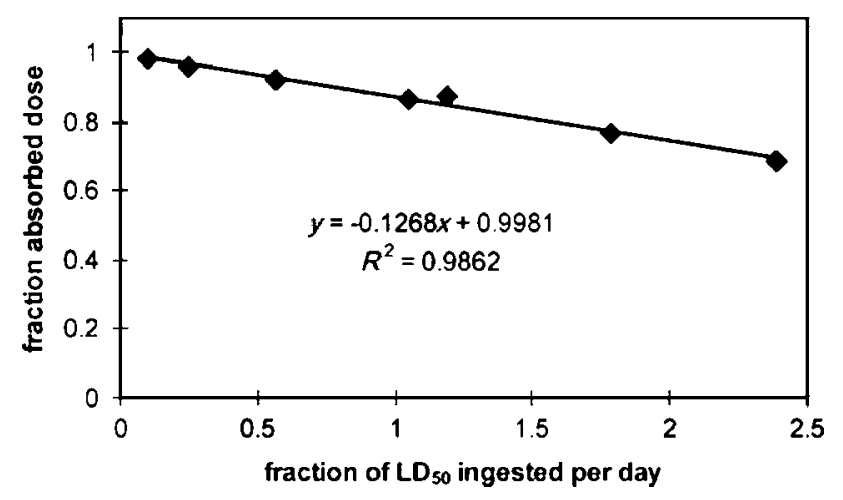

Figure 4. Linear regression for fraction of absorbed CPTH dose versus fraction of $L_{50}$ ingested per day.

calculation of a first-order elimination constant $\left(k_{\text {elim }}\right)$ for each treatment group:

$$
k_{\text {elim }}=-\ln \text { (fraction absorbed/time to death) }
$$

When $t$ is expressed in days, $k_{\text {elim }}$ equals the fraction of ingested dose that was excreted each day and $1-k_{\text {elim }}$ equals the fraction of dose that was absorbed (retained) each day. To permit application of these data to other avian species, for each treatment group, mean total dose per bird was converted to mean fraction of $\mathrm{LD}_{50}$ ingested per bird per day. The linear regression of fraction $\mathrm{LD}_{50}$ ingested versus fraction dose absorbed data yielded a regression equation with a slope of $-0.1268(P>0.999)$, intercept of 0.9981 and $r^{2}$ of 0.9862 (Fig 4):

$$
\begin{aligned}
& \text { fraction of dose absorbed }=(-0.1268 \\
& \left.\times \text { fraction } \mathrm{LD}_{50} \text { ingested }\right)+0.9981
\end{aligned}
$$

To determine whether the relationship expressed in eqn (2) is applicable to other species, this linear regression equation was used to calculate the fraction of dose absorbed for redwing blackbird and dark-eyed juncos which were gavaged with ${ }^{14} \mathrm{C}$-labeled CPTH. ${ }^{15}$ For this experiment, the fraction of dose absorbed was calculated as the total amount of CPTH-derived radioactivity in tissues divided by the total amount of radioactivity administered to each bird.

\subsubsection{Model termination}

The number of rice seeds consumed by birds feeding on the bait site was estimated by dividing the weight of bait consumed ( $\mathrm{g}$ ) by the average weight of a rice grain $(0.02334 \mathrm{~g})$.

For each iteration of the model, the number of rice seeds consumed by each bird was calculated as the sum of each day's consumption. For consecutive iterations (different birds), the total number of seeds consumed was tabulated using a macro written for Microsoft Excel. ${ }^{18}$ The model terminated when the total number of bait seeds consumed exceeded or equaled the number of bait seeds applied.

\section{RESULTS}

For blackbirds administered CPTH at a mean dose of $4.0 \mathrm{mg} \mathrm{kg}^{-1}$ bodyweight, $94 \%$ of the administered dose was absorbed (Table 1). ${ }^{15}$ Using eqn (2), the expected fraction absorbed for this relative dose $\left(1.18 \mathrm{LD}_{50}\right)$ was $91 \%, 3 \%$ less than the observed amount absorbed. For dark-eyed juncos administered CPTH at a mean dose of $17.0 \mathrm{mg} \mathrm{kg}^{-1}, 99 \%$ of the administered dose was absorbed. This is identical to the expected fraction absorbed for this relative dose $\left(0.1 \mathrm{LD}_{50}\right)$. For both species, the observed fraction of dose absorbed was not significantly different from the regression calculated values (two-tailed Student's $t$-test, $2 d \mathrm{f}, P=0.05$ ).

The mortality results presented in Table 2 were generated for a single species of bird feeding on a site baited with $26 \mathrm{lb}(11.8 \mathrm{~kg})$ of CPTH rice bait ( $1 \mathrm{lb}$ of $2 \% \mathrm{CPTH}$-treated rice and $25 \mathrm{lb}$ of

\begin{tabular}{|c|c|c|c|}
\hline Species & $\begin{array}{c}\text { Mean } \\
\text { Mortality } \\
(\%)\end{array}$ & $\begin{array}{l}\text { Birds } \\
\text { killed per } \\
\text { lb of bait } \\
\text { consumed }\end{array}$ & $\begin{array}{c}\text { Days } \\
\text { of } \\
\text { baiting }\end{array}$ \\
\hline \multirow[t]{5}{*}{ Red-winged blackbird } & 58.7 & 324 & 1 \\
\hline & 66.7 & 310 & 2 \\
\hline & 73.9 & 303 & 3 \\
\hline & 80.1 & 295 & 4 \\
\hline & 84.9 & 285 & 5 \\
\hline \multirow[t]{5}{*}{ Mourning dove } & 84.2 & 64.0 & 1 \\
\hline & 88.2 & 63.9 & 2 \\
\hline & 92.4 & 63.5 & 3 \\
\hline & 94.8 & 63.3 & 4 \\
\hline & 96.8 & 63.0 & 5 \\
\hline
\end{tabular}
diluent rice) per day. Percentage mortalities were

Table 2. Days of baiting versus mortality statistics

Probability of revisiting bait site on subsequent baiting days $=50 \%$. 


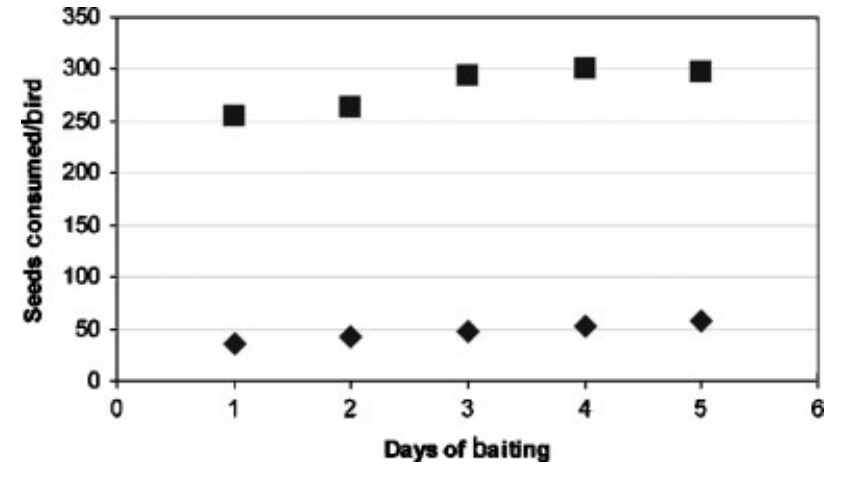

Figure 5. Mean seed consumption versus days of CPTH baiting: mourning dove, $(\boldsymbol{\nabla})$ red-winged blackbird.

higher for mourning doves (non-target species) than for blackbirds (target species). However, the number of birds killed per pound of bait ingested by each species was about five times greater for blackbirds than for mourning doves. Increasing the number of baiting days increased the predicted mean mortalities for all species. For a single day of baiting, the mean predicted percentage mortality ranged from $58.7 \%$ for red-winged blackbirds to $84.2 \%$ for mourning doves. For 5 days of baiting, the mean predicted percentage mortality was $84.9 \%$ for red-winged blackbirds and $96.8 \%$ for mourning doves. For each species, the number of seeds consumed and ingested dose of CPTH increased with increasing number of days baiting (Figs 5, 6).

For red-winged blackbirds and mourning doves simultaneously feeding on a bait site, the model

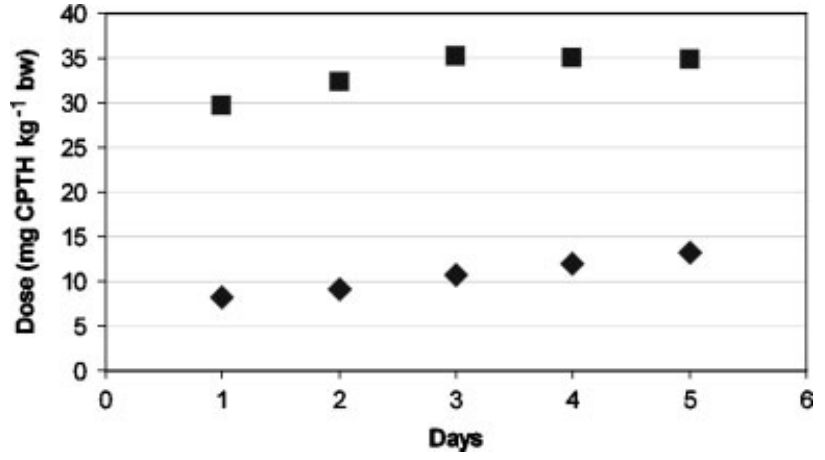

Figure 6. Mean ingested dose versus days of CPTH baiting: mourning dove, $(\boldsymbol{\nabla})$ red-winged blackbird.

can render mortality predictions for each group of the population (Table 3). The theoretical exposed population was based on the prevalence of blackbirds and mourning doves observed in bait site monitoring of Louisiana rice fields from 2002 to $2003 .{ }^{16}$ This population consisted of $99.92 \%$ red-winged blackbirds and $0.08 \%$ mourning doves. The mean percentage mortality estimates for each group were extremely similar to the estimates for a single species feeding on a bait site (Table 2). For this mixed population feeding on a bait site baited with 26 pounds of CPTH bait on 1 day, the model predicted that mortality would include approximately 323 blackbirds and 0.27 mourning doves per pound of CPTH rice bait consumed. For baiting on 5 consecutive days, the increase in mortality was less than proportional as the model mortality predictions include 265 blackbirds

Table 3. Effect of revisiting bait site on mortality

\begin{tabular}{|c|c|c|c|c|}
\hline \multirow[b]{2}{*}{ Species } & \multirow[b]{2}{*}{$\begin{array}{l}\text { Days of } \\
\text { baiting }^{a}\end{array}$} & \multirow[b]{2}{*}{$\begin{array}{c}\text { Mean } \\
\text { mortality (\%) }\end{array}$} & \multirow[b]{2}{*}{$\begin{array}{l}\text { Number of birds killed } \\
\text { per lb CPTH of rice bait }\end{array}$} & \multirow{2}{*}{$\begin{array}{c}\text { Target } \\
\text { Non-target } \\
(\%)\end{array}$} \\
\hline & & & & \\
\hline \multicolumn{5}{|l|}{ Revisit probability = 50\% } \\
\hline Red-winged blackbird & 1 & 57.6 & 233.3 & 92.92 \\
\hline Mourning dove & & 84.4 & 0.27 & \\
\hline Red-winged blackbird & 2 & 66.7 & 300.2 & 99.91 \\
\hline Mourning dove & & 88.8 & 0.27 & \\
\hline Red-winged blackbird & 3 & 73.5 & 287.0 & 99.91 \\
\hline Mourning dove & & 94.3 & 0.27 & \\
\hline Red-winged blackbird & 4 & 79.7 & 276.5 & 99.91 \\
\hline Mourning dove & & 99.9 & 0.26 & \\
\hline Red-winged blackbird & 5 days & 84.7 & 264.5 & 99.91 \\
\hline Mourning dove & & 100 & 0.23 & \\
\hline \multicolumn{5}{|l|}{ Revisit probability = 75\% } \\
\hline Red-winged blackbird & 1 day & $57.6 \%$ & 233.3 & 99.92 \\
\hline Mourning dove & & $87.6 \%$ & 0.27 & \\
\hline Red-winged blackbird & 2 days & $73.5 \%$ & 290.6 & 99.91 \\
\hline Mourning dove & & $90.8 \%$ & 0.27 & \\
\hline Red-winged blackbird & 3 days & $83.8 \%$ & 273.2 & 99.91 \\
\hline Mourning dove & & $95.4 \%$ & 0.26 & \\
\hline Red-winged blackbird & 4 days & $90.5 \%$ & 256.3 & 99.90 \\
\hline Mourning dove & & $96.5 \%$ & 0.25 & \\
\hline Red-winged blackbird & 5 days & 94.7 & 249.8 & 99.91 \\
\hline Mourning dove & & 99.7 & 0.22 & \\
\hline
\end{tabular}

a Based on consumption of $26 \mathrm{lb}$ ( $1 \mathrm{lb}$ rice containing $2 \%$ CPTH mixed with $25 \mathrm{lb}$ of untreated rice) of CPTH rice bait per day of baiting. 
and 0.23 mourning doves. These mortality estimates were affected by the proportion of birds revisiting the bait site on subsequent baiting days. If $75 \%$ of birds consuming less than a lethal dose returned to the bait sites each day, the predicted mortalities increased to 249.8 and 0.22 birds per pound of bait for blackbirds and mourning doves, respectively.

The relative influence of the model assumptions (input variables) on mortality are summarized in Table 4. The most significant variables for blackbirds and mourning doves were the probability of revisiting the bait site on subsequent baiting days, the degree of avoidance of treated bait seeds and the number of treated bait seeds consumed per bird. Bodyweight was the next most significant variable for mourning doves. The inherent sensitivity of individual birds to CPTH toxicity was the next most significant variable. The sensitivity analysis results presented in Figs 7 and 8 illustrate the magnitude of effect of the probability of revisiting bait site and the avoidance of treated seeds on percentage mortality.

In testing the validity of the bait seed consumption distribution assumptions used for this model, the mortality distribution model outputs were compared using the model seed consumption inputs versus necropsy collected bait seed consumption data (Pipas PA, pers comm, 2004) for the 1- and 5-day baiting scenarios. For each comparison, differences for mean mortality were less than $5 \%$ and standard deviations differed by less than $1 \%$.

Table 4. Sensitivity analysis - input variable contribution to probability of mortality variance

\begin{tabular}{lcc}
\hline & \multicolumn{2}{c}{ Contribution (\%) } \\
\cline { 2 - 3 } Model Input Variable & $\begin{array}{c}\text { Red-winged } \\
\text { blackbird }\end{array}$ & $\begin{array}{c}\text { Mourning } \\
\text { dove }\end{array}$ \\
\hline Probability of revisiting bait site & 11.4 & 9.0 \\
Avoidance of treated seed & 8.9 & 8.1 \\
Number of treated seeds consumed & 7.9 & 10.9 \\
Total seed consumption & 2.5 & 3.9 \\
Bodyweight & $<0.1$ & 2.2 \\
Log LD50 & 0.4 & 0.8 \\
\hline
\end{tabular}

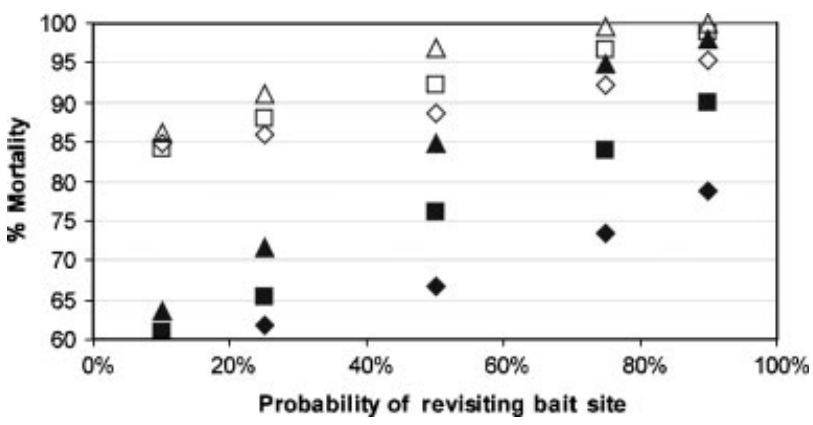

Figure 7. Probability of revisiting bait site versus percent mortality for red-winged blackbirds: ( 2 days, ( $\mathbf{\square}) 3$ days, ( 5 days of baiting, and mourning doves $(\diamond) 2$ days, $(\square) 3$ days, (O) 5 days of baiting.

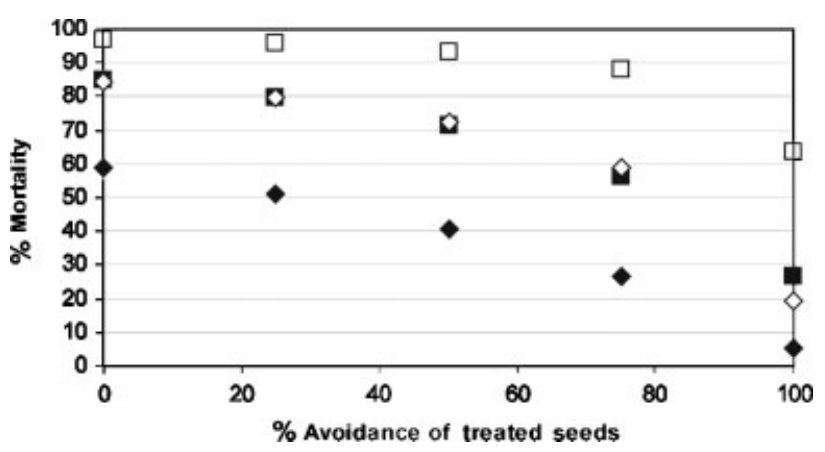

Figure 8. Percentage mortality versus avoidance of treated seeds for red-winged blackbirds: $(\boldsymbol{}) 2$ days, ( $\mathbf{\square}) 5$ days of baiting, and mourning doves $(\diamond) 2$ days, $(\square) 5$ days of baiting.

\section{DISCUSSION}

Hazard identification, exposure assessment, dose versus response assessment and risk characterization are the four steps comprising the widely accepted paradigm for risk assessment. ${ }^{19}$ As CPTH exhibits varying degrees of toxicity to most bird species, this chemical represents a potential hazard to many species of birds. ${ }^{4}$ For a typical agricultural baiting situation, the most significant route of exposure is oral, so exposure was estimated by predicting the quantity of CPTH ingested by birds feeding on bait sites. Dose versus mortality analyses were performed using previously published data.

For this model, we felt that red-winged blackbirds and mourning doves represented the most logical target and non-target species, respectively. CPTHtreated rice baits are commonly used to reduce blackbird damage on rice and sunflower. ${ }^{2-7,11,12}$ In a multi-year survey of non-target species observed in CPTH-baited rice fields in Louisiana and Texas, Savannah sparrows, killdeer and mourning doves were the most frequently observed species. Other non-target species included meadowlarks, northern cardinals and snow geese. ${ }^{7}$ In addition, several species of sparrow have been observed in CPTH-baited sunflower seeds in the Dakotas. ${ }^{6}$ In single-choice CPTH-treated rice seed caged feeding studies with Savannah sparrows, song sparrows, field sparrows and snow geese, no mortality was observed. Other than weight losses ranging from 2 to $5 \%$, no sub-lethal effects were noted during these studies. ${ }^{12}$ This suggests that, due to low sensitivity to the toxicant, these species are not at significant risk of mortality. Killdeer are insectivorous and consume virtually no rice seed (Pipas PA, pers comm, 2004); killdeer exposure to CPTH would be expected to be negligible. The toxicity of CPTH is virtually identical for meadowlarks $\left(\mathrm{LD}_{50}=4.1 \mathrm{mg} \mathrm{kg}^{-1}\right)$, northern cardinals $\left(\mathrm{LD}_{50}=3.2 \mathrm{mg} \mathrm{kg}^{-1}\right)$ and mourning doves $\left(\mathrm{LD}_{50}=4.1 \mathrm{mg} \mathrm{kg}{ }^{-1}\right) .{ }^{17}$ However, meadowlarks and northern cardinals generally consume at least an order of magnitude less rice seed bait than do mourning doves (Pipas PA, pers comm, 2004); exposure of meadowlarks and northern cardinals to CPTH would be at least ten times less 
than for mourning doves. This analysis indicates that, due to a combination of significant exposure and sensitivity, mourning doves are likely the non-target species at greatest risk of CPTH-associated mortality.

For this study, bait consumption was estimated by combining and subsequently extrapolating consumption data from confined feeding studies and necropsy results from limited samples of field-collected birds. Other approaches considered include bio-energetic based estimates of consumption or empirical data derived from necropsy analysis of field-collected birds. The bio-energetic approach was not pursued because field observations of feeding behavior indicated that consumption of the rice seed bait constitutes approximately 4-5 min of an entire day's feeding for a bird (Pipas PA, pers comm, 2004 and Reference 11); attempting to correlate bait seed consumption during this brief period of gorge feeding to daily energy requirements seemed unwise because there are no data to suggest that quantity of food consumed during several minutes of gorge feeding is related to bio-energetic requirements. To base consumption estimates on empirically derived consumption data would require significant resources to harvest and necropsy a large number of birds post-feeding. In addition, the process of collecting birds on bait sites has the potential to bias the data leading to underestimation of consumption; birds may be collected before they have completed their normal bout of feeding. Furthermore, basing exposure predictions on sitespecific, empirically derived consumption data may lead to a geographically and temporally restrained model. However, the consumption inputs used for this model resulted in percentage mortality predictions that were only $0.3-5 \%$ higher than the predictions generated using necropsy-derived consumption data. This implies that the species-specific seed consumption assumptions used for this model are valid and illustrates the potential value (and cost savings) of creatively combining and applying post hoc analyses to previously published data.

Dose versus response (percentage mortality) was determined via laboratory feeding trials; groups of birds were dosed with varying amounts of CPTH and the percentage mortality was recorded at each dose level. By incorporating the variability associated with this dose versus response regression into the model, mortality was estimated for individual exposures and individual sensitivities to $\mathrm{CPTH}$. As an individual bird's sensitivity to CPTH exposure will almost always differ from the mean estimated sensitivity of the exposed population, this model offers a more realistic assessment of CPTH-related mortality than the commonly used approach of applying the population-based dose versus response regression to all individuals. This approach is especially valuable for determining the risk of mortality for small populations of exposed (presumably non-target) species.
The risk characterization process traditionally combines exposure assessment and dose versus response results to quantify the risk for the exposed individuals and/or populations. Deterministic approaches have traditionally been used to complete the risk-assessment process; single fixed values are utilized as exposure and toxicity estimates to yield a single measurement for risk. ${ }^{20}$ These exposure values are typically subjective (ie 90 th, 95 th or 100 th percentile) exposure estimates. The result often errs on the side of overestimating the risk to (ie protecting) humans and other non-target species.

Probabilistic approaches permit the quantification of variability and uncertainty on risk by incorporating the full range of exposure and dose versus response data into the risk characterization. This permits risk assessors to estimate the probabilities associated with different target levels of effect such as percentage mortality or numbers of individuals killed. This type of risk assessment output can be very useful for evaluating exposure scenarios associated with moderate to low levels of risk such as those accompanying the application of pesticides to agricultural settings.

To use a vertebrate pesticide legally in the USA, the pesticide formulation must be successfully registered with the US Environmental Protection Agency. One registration guideline is the demonstration (under field conditions) of a minimum efficacy of $70 \%$ with respect to the target species when the pesticide is applied according to the proposed use guidelines. ${ }^{21}$ For pesticides such as rodenticides, efficacy can be demonstrated by straightforward field studies in which pest rodent populations in field study plots are estimated before and after application of the rodenticide. However, with respect to the use of $\mathrm{CPTH}$ to control pest bird populations, it is highly problematic, if not impossible, to conduct a field baiting study and subsequently determine the number or percentage of CPTH-exposed birds that live or die; in monitoring field sites for several days after consumption of CPTH baits, very few target or nontarget lethalities are detected.

Conducting such a study in an aviary would also be problematic due to the limited number of birds that could be exposed, the limited choice of alternative forage available to the birds, the inability to duplicate the choice of birds to return to the feeding sites on multiple days, and the likely decreased energy expenditure of birds in an aviary. The probabilistic modeling approach used in the present study offers a means to determine the percentage mortality of a variety of species associated with the application of CPTH under field conditions. For this model, the full range of dose versus mortality data and seed consumption data for the species of interest were used. Outputs included the probabilities and associated variability for the range of CPTH consumption (dose) and associated predicted mortality for birds feeding on CPTH bait sites (Fig 9, Tables 2, 3). While more than 

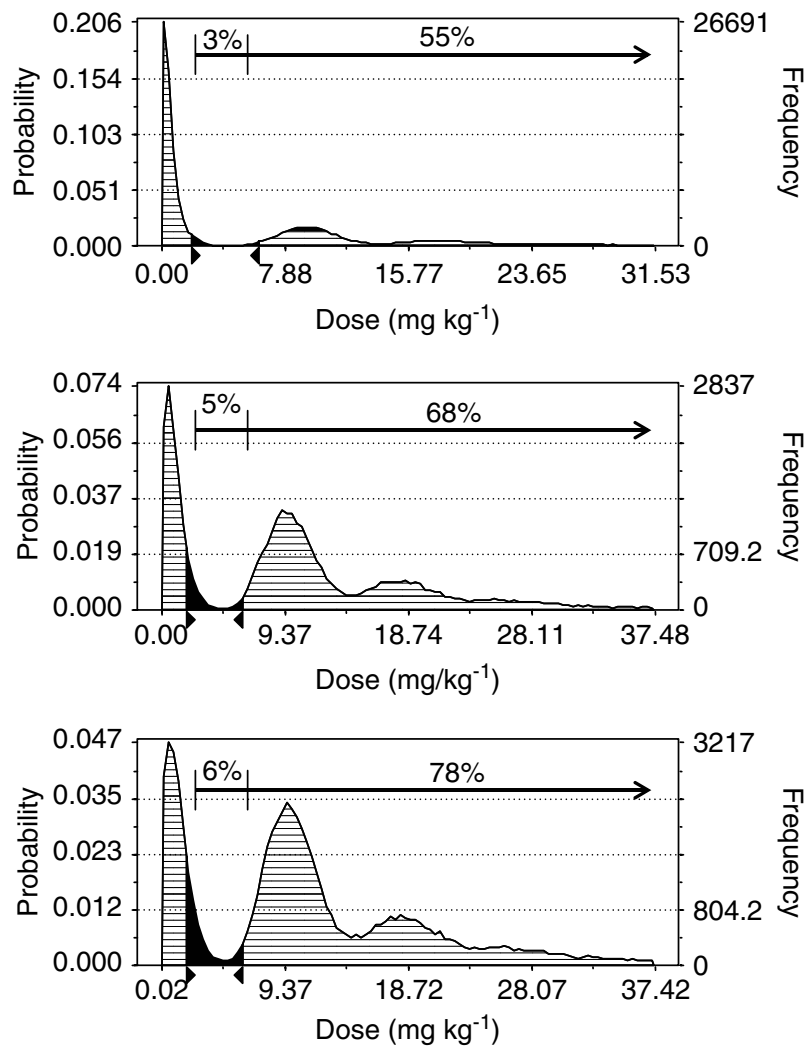

Figure 9. Frequency distribution of CPTH dose for blackbirds: (top) 1 , (middle) 3 and (bottom) 5 days of baiting. $L_{L} D_{1}<L_{99}$.

95\% of ingested CPTH is excreted within $6 \mathrm{~h}$ postexposure, ${ }^{15}$ the cumulative nature of $\mathrm{CPTH}$ poisoning in sensitive species is likely due to irreversible kidney damage resulting from the binding of reactive metabolites to kidney cells. However, the effective dose or percentage absorption does not appear to be proportional to the quantity ingested. As is typical for many drugs and toxicants, the percentage effective dose or percentage absorption appears to decrease with increasing dose. For CPTH ingestion by starlings, this relationship was modeled using eqn (2). Prior to model execution, it was imperative to determine whether eqn (2) was applicable to other avian species. For blackbirds and juncos ingesting mean doses of $4.0 \mathrm{mg} \mathrm{kg}^{-1}$ and $17.0 \mathrm{mg} \mathrm{kg}^{-1}$, respectively, the observed fraction of the doses absorbed was not significantly different from the regression calculated values (two-tailed Student's $t$-test, $2 d f, P=0.05$; Table 1). Based on this analysis, this equation was applied to red-winged blackbirds and mourning doves to calculate the effective cumulative $\mathrm{CPTH}$ dose for multiple day exposures.

To determine CPTH exposure, the full range of the bait seed consumption distribution (seeds ingested per bird) for each species was used as a model input. Based on this input and the ratio of treated:diluent bait seeds, the numbers of treated and diluent seeds consumed per bird were estimated (Figs 2 and 5). Avoidance of pesticide-treated food or bait has been documented for many pesticides and is frequently included in deterministic exposure assessments. ${ }^{13}$ In confined feeding studies, five out of six species of birds consumed $23-90 \%$ less CPTH treated baits (1:25 2\% CPTH rice:untreated rice) than control (untreated) rice seed. For all species, the mean consumption of a 1:25 mixture of treated:untreated seeds was $55 \%$ less than untreated seeds only. ${ }^{12}$ While this provides evidence for avoidance of CPTHtreated seeds, the ratio of treated to untreated rice grains consumed has never been demonstrated. To determine the impact of avoidance on mortality, sensitivity analyses were conducted by executing the model with levels of avoidance (of treated seeds) ranging from 0 (no avoidance) to $100 \%$ avoidance of treated seeds. The predicted impact of avoidance on the mortality can be quite significant (Fig 8). For 1 -day baiting scenarios, $50 \%$ versus $100 \%$ avoidance of treated seeds reduced relative percentage mortality by approximately $30 \%$ for red-winged blackbirds and mourning doves. For the 5-day baiting scenario, the impact was about half as great. This analysis indicates that improved quantification of avoidance of CPTHtreated rice seeds would increase the accuracy of mortality predictions.

The only input variable that had a greater impact than treated seed avoidance on the predicted level of mortality was the probability that a bird would revisit a bait site on subsequent baiting days (Table 4). As illustrated in Fig 7, the predicted impact of this variable increased with an increase in the number of baiting days. For example, the model predicted that the probability of a red-winged blackbird revisiting a bait site can impact the relative target mortality by as much as $45 \%$; for the 5 -day baiting scenario, the predicted mortality for red-winged blackbirds ranged from $67 \%$ (10\% probability of revisit/day) to $97 \%$ ( $90 \%$ probability of revist/day). For the 2-day baiting scenario, the same increase in probability of revisiting a bait site increased the relative predicted mortality by $25 \%$. The effect was less significant for mourning doves because mourning doves consumed lethal doses more quickly than did red-winged blackbirds; once a lethal dose is consumed, the probability that a bird will revisit the bait site is irrelevant.

Previous non-target CPTH exposure and risk assessments assumed that no CPTH exposure was associated with the ingestion of diluent rice seed. ${ }^{4,6,22}$ However, we recently demonstrated that CPTH can be transferred from the treated to the diluent seeds during mixing. Chemical analysis of individual seeds generated a distribution of CPTH residues on both treated and diluent rice seed. After $3 \mathrm{~min}$ of mixing (normal field procedures), approximately 15\% of the CPTH on treated seed was transferred to the diluent seed, resulting in a normal CPTH content distribution with a mean ( \pm standard deviation) of $86.6( \pm 17.3) \%$ of the target concentration for treated rice and 0.5 $( \pm 0.24) \%$ of target for diluent rice. The distributions of CPTH on treated and diluent seeds were used to generate the distribution of doses required to complete the probabilistic based mortality predictions (Fig 9). 
For the dose versus percentage mortality curves constructed for this study (based on laboratory toxicity studies), the percentage mortality data points for each dose level deviated from the best fit regression line. Individual differences in sensitivity to the test compound contributed to this variability. This variability was incorporated into the dose versus mortality portion of the model by generating a new dose versus response curve for each exposure (Fig 2). This was accomplished by randomly selecting slope and median dose values from distributions based on the mean values and associated variabilities in the original dose versus response experiment. The probability of mortality for each bird was then determined from the dose and dose versus mortality regression for each bird.

The fact that a bird which ingests a sub-lethal dose of CPTH can return to the bait site on subsequent days and ingest the remainder of a lethal dose is reflected in the model's prediction that percentage mortality increased as the number of days of baiting increased (Fig 9). For example, for a population of blackbirds, after 1 day of baiting, $43 \%$ have ingested a dose greater than that associated with $99 \%$ probability of death. At 3 days of feeding on bait sites, $68 \%$ of the population has ingested a dose greater than this value. By 5 days of bait site feeding, this number increases to $74 \%$ of the population.

The model predicted that the fraction of exposed birds receiving a sub-lethal dose decreased with additional baiting days while the fraction of birds receiving greater than a lethal dose $\left(>\mathrm{LD}_{99.9}\right)$ increased (Fig 9). With multiple baiting days, CPTH is used less efficiently as birds consume multiple lethal doses. Thus, the predicted number of birds killed per unit weight ingested bait decreased with increasing number of baiting days because the number of seeds ingested per bird increased. These relationships suggest that, given the current use practices for CPTH baiting, 3 days of baiting may represent a compromise between achieving maximum population reduction per unit weight bait while still achieving a minimum of $70 \%$ efficacy, the required minimum efficacy for pesticide use in the USA.

Potential non-target effects are illustrated by the model's predictions for CPTH-exposed mourning doves. A comparison of dose versus mortality curves suggests that mourning doves are only slightly more resistant (less sensitive) to $\mathrm{CPTH}$ than are blackbirds; the $\mathrm{LD}_{50}$ for mourning dove is $4.1 \mathrm{mg} \mathrm{kg}^{-1}$ while the $\mathrm{LD}_{50}$ for blackbirds is $3.4 \mathrm{mg} \mathrm{kg}^{-1}$. However, the predicted percentage mortality for mourning doves is much higher than for blackbirds for every CPTH baiting scenario (Table 2) because mourning doves consume significantly more bait and $\mathrm{CPTH}$ per unit bodyweight (Figs 5 and 6). These results illustrate an advantage of the probabilistic approach compared with deterministic risk evaluations. A commonly used deterministic approach for estimating risk to wildlife is to calculate the number of $\mathrm{LD}_{50}$ s per square foot. Assuming a mean $\mathrm{CPTH}$ concentration of $15.4 \mu \mathrm{g}$ CPTH per seed ( $400 \mu \mathrm{g} \mathrm{CPTH} \mathrm{per} \mathrm{treated}$ seed diluted 1:25 with untreated seeds), mean bodyweights of $50 \mathrm{~g}$ for blackbirds and $119 \mathrm{~g}$ for mourning doves and $\mathrm{LD}_{50}$ values of 3.4 and $4.1 \mathrm{mg} \mathrm{kg}^{-1}$ body weight for blackbirds and mourning doves, respectively, an $\mathrm{LD}_{50}$ exposure would required 11 seeds for a blackbird and 32 seeds for a mourning dove. Assuming a broadcast rate of 10 seeds per square foot, the estimated number of $\mathrm{LD}_{50}$ s for blackbirds and mourning doves are 0.91 and 0.3 per square foot. By failing to capture the distributions of CPTH on the treated and diluent rice seeds and species-specific seed consumption distributions, this commonly used deterministic approach inappropriately suggests that the risks are greater for black birds than mourning doves.

To minimize non-target fatalities associated with CPTH baiting, non-target exposure should be minimized. The current practices of timing CPTH bait application to maximize exposure of targets and minimize non-target exposure should be continued. The desirable effects of this practice are illustrated in Table 3; even though more than $84 \%$ of CPTHexposed mourning doves die, mourning doves represent $0.1 \%$ or less of birds killed because baits are applied when and where mourning dove populations are minimal. Application of this probabilistic model to other non-target species will permit quantification of the risks associated with other potentially exposed non-target species. With this information, applicators can apply CPTH in a manner to minimize exposure of species that are at significant risk of $\mathrm{CPTH}$-induced mortality.

The sensitivity analysis presented in Table 4 reinforces the observation that the number of seeds consumed has a significant impact on mortality and that the impact is greatest on the early days of baiting. This suggests that a way of affecting mortality associated with CPTH baiting is to influence the seed consumption, especially on the initial days of baiting. This is can be accomplished by pre-baiting with untreated rice. Pre-baiting would also permit applicators to screen for the presence of susceptible non-target species. A wide variety of factors that influence consumption, such as the selection of bait grain size, addition of colorants, presentation of alternative food sources, timing of bait placement and proximity of baiting sites to roosting sites, have previously been studied. ${ }^{23,24}$ Determining the impact of these factors on model inputs such as treated seed avoidance and/or seed consumption would permit the estimation of the impact of these approaches on target and non-target mortality, leading to a combination of techniques to maximize the benefits and minimize undesirable effects associated with the application of CPTH rice baits.

\section{CONCLUSIONS}

Previously, it has not been possible to determine percentage mortality and the number of target and 
non-target birds killed as a result of CPTH baiting operations. The probabilistic model presented here offers the best approach to date for estimating these important criteria. Application of this model will permit the design of baiting protocols which conform to EPA pesticide use requirements and maximize the benefit-to-risk ratios for the important avicide CPTH. Application of this model to other target and nontarget species would require the identification of data to permit estimation of bait seed consumption and CPTH sensitivity. Once these data are incorporated in the model for species representative of all species of interest, site and date specific mortality, estimates can be conducted by providing model inputs for the proportions of species feeding on the bait site and the quantity of bait consumed.

Finally, the model's conclusions provide a means for prioritization of future research to improve the ability to predict mortality associated with $\mathrm{CPTH}$ rice baiting operations. Experiments designed to determine the species-specific relative avoidance of CPTH-treated seeds and the species-specific probability of revisiting bait sites on subsequent baiting days would increase the accuracy of the model predictions.

\section{REFERENCES}

1 DeCino TJ, Cunningham DJ and Schafer EW, Toxicity of DRC-1339 to starlings. $\mathcal{F}$ Wildife Manag 30:249-253 (1966).

2 Glahn JF and Wilson EA, Effectiveness of CPTH baiting for reducing blackbird damage to sprouting rice. Proc Eastern Wildlife Damage Control Conf 5:17-123 (1992).

3 Linz GM and Bergman DL, DRC-1339 avicide fails to protect ripening sunflowers. Crop Prot 15:307-310 (1996).

4 Eisemann JD, Linz GM and Johnston JJ, Non-target hazard assessment of using DRC-1339 avicide to manage blackbirds in sunflower, in Pesticides and wildife, ed by Johnston JJ, ACS Books, Washington, DC, pp 197-211 (2001).

5 Linz GM, Kenyon MJ, Holman HJ and Bleier WJ, Avian use of rice-baited corn stubble in east-central South Dakota. Int Biodet Biodeg 49:179-184 (2002).

6 Custer TW，Custer CM，Dummer IM，Linz GM，Sileo L Stahl RS and Johnston JJ, Nontarget bird exposure to DRC1339 during fall in North Dakota and spring in South Dakota, in Management of North American blackbirds, ed by Linz GM, National Wildlife Research Center, Fort Collins, CO, pp 64-70 (2003).

7 Pipas PA, Cummings JL, Eisemann JD and Engeman RM, Nontarget bird use of DRC-1339 bait sites during operational baiting programs in Louisiana and Texas, in Management of North American blackbirds, ed by Linz GM, National Wildlife Research Center, Fort Collins, CO, pp 71-78 (2003).

8 Plumart $\mathrm{P}$, The intersection of public policy and blackbirds using the Department of Agriculture's blackbird-poisoning program, in Management of North American blackbirds, ed by Linz GM, National Wildlife Research Center, Fort Collins, CO, pp 15-17 (2003).
9 Johnston JJ, Hurlbut DB, Avery ML and Rhyan JC, Methods for the diagnosis of acute 3-chloro- $p$-toluidine hydrochloride poisoning in birds and the estimation of secondary hazards to wildlife. Environ Toxicol Chem 18:2533-2537 (1999).

10 Denning JB, Body weights of 686 species of North American Birds, Monograph No 1, Western Bird Banding Association, US Department of Interior, US Fish and Wildlife Service, Fort Collins, CO, $38 \mathrm{pp}$ (1984).

11 Avery ML and Glahn JF, Estimation of red-winged blackbird mortality from toxic bait application, in Pesticides and wildlife, ed by Johnston JJ, ACS Books, Washington, DC, pp 109-118 (2000).

12 Cummings JL, York DL, Shively KJ, Pipas PA, Stahl RS and Davis JE, Dietary toxicity test for $2 \%$ DRC-1339-treated brown rice on nontarget avian species, in Management of North American blackbirds, ed by Linz GM, National Wildlife Research Center, Fort Collins, CO, pp 79-84 (2003).

13 Hart A, Probabilistic assessment of pesticide risks to birds, in Environmental fate and effects of pesticides, ed by Coats JR and Yamamoto H, ACS Books, Washington, DC, pp 271-286 (2003).

14 Schaefer EW, Brunton RB, Cunningham DJ and Lockyer NF, The chronic toxicity of 3-chloro-4-methylbenzamine $\mathrm{HCl}$ to birds. Arch Environ Contam Toxicol 6:241-248 (1977).

15 Goldade DA, Johnston JJ and Tessari JD, Distribution of a radio-labeled avicide in two species of birds following a single oral dose, in Management of North American blackbirds, ed by Linz GM, National Wildlife Research Center, Fort Collins, CO, pp 112-113 (2003).

16 Finney DJ, Probit analysis, 3rd edn. Cambridge University Press, Cambridge, UK (1971).

17 Eisemann JD, Pipas PA and Cummings JL, Acute and chronic toxicity of the compound DRC-1339 (3-chloro4-methylaniline hydrochloride) to birds, in Management of North American blackbirds, ed by Linz GM, National Wildlife Research Center, Fort Collins, CO, pp 49-63 (2003).

18 Microsoft Excel, Microsoft, Redmond, WA (2002).

19 National Research Council, Risk assessment in the Federal Government: managing the process, National Academy Press, Washington, DC, $191 \mathrm{pp}$ (1983).

20 Urban DJ and Cook NJ, Hazard Evaluation Division Standard Evaluation Procedure: Ecological Risk Assessment, EPA 540/9-85-001, Office of Pesticide Programs, United States Environmental Protection Agency, Washington, DC, 96 pp (1986).

21 Schneider BA, Pesticide Assessment Guidelines, Subdivision G, Product Performance, US Environmental Protection Agency publication 540/9-82-026, US Environmental Protection Agency, Office of Pesticides and Toxic Substances, Washington, DC, p 296 (1982).

22 Avery ML, Kenyon MJ, Linz GM, Bergman DL, Decker DG and Humphrey JS, Potential risk to ring-necked pheasants from application of toxic bait for blackbird control in South Dakota. 7 Wildlife Manag 62:388-394 (1998).

23 Avery ML, Humphrey JS, Decker DG and McGrane AP, Seed color avoidance by captive red-winged blackbirds and boat-tailed grackles. f Wildife Manag 63:1003-1008 (1999).

24 Linz GM, Homan HJ and Wimberly RL, Avian use of various bait mixtures offered in cornfields during spring migration in South Dakota, in Pesticides and wildlife, ed by Johnston JJ, ACS Books, Washington, DC, pp 345-358 (2001). 